NBER WORKING PAPER SERIES

\title{
DISABILITY INSURANCE REJECTION \\ RATES AND THE LABOR SUPPLY \\ OF OLDER WORKERS
}

Jonathan Gruber

Jeffrey D. Kubik

Working Paper No. 4941

\section{NATIONAL BUREAU OF ECONOMIC RESEARCH 1050 Massachusetts Avenue \\ Cambridge, MA 02138 \\ November 1994}

We are grateful to John Bound, Dora Costa, Peter Diamond, and Jerry Hausman for helpful discussions and to Donald Parsons for providing data. This paper is part of NBER's research programs in Aging, Health Care, Labor Studies, and Public Economics. Any opinions expressed are those of the authors and not those of the National Bureau of Economic Research.

(c) 1994 by Jonathan Gruber and Jeffrey D. Kubik. All rights reserved. Short sections of text, not to exceed two paragraphs, may be quoted without explicit permission provided that full credit, including $\odot$ notice, is given to the source. 


\title{
DISABILITY INSURANCE REJECTION \\ RATES AND THE LABOR SUPPLY \\ OF OLDER WORKERS
}

\begin{abstract}
Disability Insurance (DI), which provides income support to disabled workers, has been criticized for inducing a large fall in the labor force participation rate of older workers. We study the effects of one policy response designed to address this moral hazard problem: raising the rate at which DI claims are denied. Initial DI applications are decided at the state level, and, in response to a funding crisis for the DI program in the late 1970s, the states raised their rejection rates for first time applicants by $30 \%$ on average. The extent of this rise, however, varied substantially across states. We use this variation to estimate a significant reduction in labor force non-participation among older workers in response to denial rate rises. A $10 \%$ increase in denial rates led to a $2.7 \%$ fall in non-participation among $45-64$ year old males; between $1 / 2$ and $2 / 3$ of this effect is a true reduction in labor force leaving, with the remainder accounted for by the return to work of denied applicants. We find some support for the notion that increases in denial rates effectively target their incentive effects to more able individuals; the fall in labor force non-participation was much stronger among more able workers, according to an anthropometric measure of disability.
\end{abstract}

Jonathan Gruber

Department of Economics, E52-274c

M.I.T.

Cambridge, MA 02139

and NBER
Jeffrey D. Kubik

Department of Economics

M.I.T.

Cambridge, MA 02139 
Disability Insurance (DI) is one of the largest social insurance programs in the U.S., with over 5 million beneficiaries and benefit payments of over $\$ 36$ billion (New York Times, April 8, 1994). In theory, this program provides income support to workers who are unable to continue employment due to physical disability. The difficulty of defining disability, however, as well as the generosity of potential benefits under the DI program has led many analysts to question whether DI is distorting labor supply decisions among those able to work. As Parsons (1980) and others have noted, the rapid growth in the DI program during the 1960 s and 1970 s closely parallels the rapid rise in labor force non-participation among older male workers.

This potential moral hazard problem would ideally be resolved by improving the precision of the screening process used by the DI program. Barring this, there are a number of second-best approaches to addressing the problem and slowing program growth. The approach which has received the most attention in the empirical economics literature is a reduction in the benefits available to the disabled. A number of articles have found that cutting benefits will slow the rate at which older workers leave the labor force and enter the DI program, but the estimated effect on these flows varies widely. This variation may reflect the fundamental difficulty in econometrically identifying the effects of DI benefit differences on worker behavior, since benefits are largely a function of the worker's earnings history, which may be correlated with work propensities for other reasons.

There are, however, a number of other policy tools available for addressing the moral hazard problem induced by imperfect screening. One natural alternative is uniformly increasing the stringency of the screening process. This alternative, however, has received much less attention in the economics literature. The purpose of this paper is to partially remedy this deficit, by estimating 
the effect of substantial increases in the DI denial rate in the late 1970 s.

As noted by Marvel (1982) and Parsons (1991a), initial DI decisions are made by state agencies, leading to substantial variation across the states in the fraction of DI applications which are (initially) granted. While individuals can appeal any decision to a higher level, initial denials represent an important stumbling block to ultimate receipt of benefits; less than $25 \%$ of DI recipients were awarded their benefits beyond the initial determination stage (U.S. Congress Committee on Ways and Means, 1993). Furthermore, appealing initial decisions is a very time consuming process (Parsons, 1991a).

In a single cross-section, variation in state denial rates reflects a number of factors, including the average health mix of the underlying applicant pool. Due to a funding crisis for DI in the late 1970s, however, there was a large increase in initial denial rates. Average denial rates rose by 15.5 percentage points $(30 \%)$, and this increase occurred at a differential rate across the states. This plausibly exogenous policy change potentially provides a more fruitful method of identification for studying the effects of DI on labor force behavior than do potential DI benefits differences across individuals. We match information on state denial rates to the National Health Interview Survey (NHIS), a large nationally representative micro survey which contains data on both the labor force participation and health status of older persons, to address two questions about the effects of denial rate changes on the labor force non-participation of 45-64 year old male workers.

First, do increases in state denial rates increase the labor supply of older workers? We find that there is a significant negative relationship between this dimension of DI generosity and labor force non-participation among $45-64$ year olds. Our estimates imply that the $30 \%$ increase in denial rates from 1977 to 1980 led to a fall in labor force non-participation among this group of 1.4 percentage points (8.1\%). Some part of this effect is due to the return to work of denied applicants; 
but correcting for this reemployment only explains (at most) $1 / 2$ of our estimate. The remaining participation response is within the range of previous estimates of the effects of changes in potential DI benefits on labor force non-participation.

Second, how well targeted were the incentive effects of increased denial rates? We use an anthropometric measure of underlying health, the Body Mass Index, to examine the differential effect of changes in denial rates on those in poor vs. non-poor health. We find that, according to this measure, increases in denial rates effectively targeted the labor force increase to individuals in better health. Under our strictest measure of disability, we find that there was no effect of this policy change on the disabled, but that the labor force non-participation of the able fell by $11.1 \%$.

The paper proceeds as follows. In Part I, we provide some background on the DI program, and review previous evidence on the effect of DI on labor force participation. In Part II, we discuss the policy change under consideration. In Part III, we describe the data and modelling strategy. Part IV presents the results on the overall effects on labor force participation, and Part V presents the results on targeting efficiency. Part VI concludes.

\section{Part I: Background on DI}

\section{Institutional Details}

DI was started in 1957 as insurance for those over 50 who suffered from an impairment that could "be expected to result in death or be of long, continued and indefinite duration." The program was then expanded to include younger individuals and the disability standard was gradually liberalized so that the definition currently hinges on an "inability to engage in substantial gainful

\footnotetext{
'Except where otherwise noted, details on the DI program are for 1992 and are from U.S. Congress, House Committee on Ways and Means (1993).
} 
activity by reason of physical or mental impairment;" this impairment must be medically determinable and last at least 12 months. Eligibility is contingent on previous labor force attachment; most applicants must have worked 20 of the 40 quarters prior to application, although the rules differ somewhat for younger applicants. However, application for DI cannot be made unless the individual has been out of work for at least five months, providing the first of several serious application barriers.

Initial awards decisions are made by state DI boards, based on a medical examination. Denied applicants are then entitled to a series of appeals, first to the state agency, then to an Administrative Law Judge who is independent of the state boards, then to an Appeals Council, and finally to the Federal court system. The award decision is well known to be a highly imperfect targeting device. In two studies reviewed by Parsons (1991b), reconsideration of initial determinations by either the same review panel one year later or a separate team of medical experts revealed substantial Type I and Type II errors.

The DI benefits for which individuals are potentially eligible are fairly generous. Benefits determination follows the same methodology as Social Security benefit calculations, with benefits computed as a (redistributive) function of past earnings history. After-tax replacement rates averaged approximately $60 \%$ by the mid-1970s (Bound, 1989).

Perhaps as a result of these generous benefits and imperfect targeting, there was a tremendous growth in the DI rolls during the 1960 s and 1970s. The number of DI recipients grew from 455,000 in 1960 to 2.8 million by 1977 , and total payments grew twentyfold (U.S. Department of Health and Human Services, 1990). At the same time, there was a dramatic decline in the labor force participation rate of older males, and the two time series moved in almost exact parallel, as documented in Parsons (1980). But drawing causal inferences from this time series data is 
problematic, as there were a number of other changes in the labor market and non-labor market opportunities of older males during this era. ${ }^{2}$

\section{Program Parameters and the Behavior of Older Workers}

A sizeable literature has attempted to use cross-sectional variation to identify the role that DI plays in the labor force participation decisions of older men. These studies generally proceed by modelling labor force participation or DI recipiency as a function of potential DI benefit levels. Parsons (1980) estimates very large disincentive effects of DI generosity, which suggest that DI program growth can explain almost all of the change in the labor force participation of older males during the era of DI expansion. Other estimates have supported the contention that DI has a significant disincentive effect, although the estimated magnitudes have generally been smaller than that of Parsons; see Leonard (1986) and Bound (1989) for reviews of this evidence.

Bound (1989) argues, however, that this type of strategy is likely to yield misleading inferences for the effect of DI generosity on labor force participation. The generosity of benefits under DI is a non-linear function of the worker's past earnings history; low income workers receive a higher replacement rate from DI. As a result, there is a fundamental identification problem in modelling the effect of potential DI benefits on work decisions: a finding that workers with higher potential DI replacement rates are more likely to leave their jobs may simply reflect differential tastes

${ }^{2}$ For example, there was rapid growth in retirement incomes in this era, both due to increased Social Security benefit levels, and increased coverage of the labor force by pensions (Lumsdaine and Wise, 1990). Bound and Waidmann (1992) attempt to surmount this problem by looking at changes in self-reported disability among job leavers before and after the broad expansion of DI in the 1960 s. They estimate that DI growth can explain as much as $80 \%$ of the rise in non-participation among $45-$ 54 year olds in the 1970s, but that for 55-64 year olds the effects ar only one-half as large. 
for work among high and low wage workers. ${ }^{3}$ Bound suggests an alternative methodology for determining the effects of DI on labor force behavior: examining the behavior of workers who apply for DI benefits, but are rejected. In theory, these workers should be at least as healthy as those who are on the program, so that their labor force participation rates provide an upper bound on the potential labor force participation of accepted workers. Bound finds, however, that less than $50 \%$ of rejected workers had returned to work by 18 months (or more) after their rejection, which suggests that DI program growth can explain no more than $40 \%$ of the rise in non-participation among older males. 4

Despite this large literature on the effects of changing DI benefit levels on older workers, there is little work on the effects of other, equally important, DI program parameters. Parsons (1991a) presents a model of the effect of changes in a number of DI policy tools on the DI applications decision. This model predicts that applications rise as benefits rise, and that they fall with increases in either the denial rate or the delay in processing applications. This suggests at least two alternative policy instruments at the disposal of DI administrators who are faced with this moral hazard problem.

We are aware of only three other studies which have estimated the impact of changing these other program parameters on the behavior of older workers. Halpern and Hausman (1986) build a detailed structural model of the decision to apply for DI benefits, which formulates the DI acceptance

\footnotetext{
${ }^{3}$ Studies such as Haveman and Wolfe (1984) attempt to correct for this omitted variables bias in a number of ways, but Bound (1989) argues that the problem has not been convincingly resolved.

The validity of denied applicants as a control group, however, rests on two key assumptions. First, these applicants must be unobservably no less likely to work than accepted applicants; Bound uses pre-application differences in characteristics to demonstrate that this is true. Second, the process of applying must have no lasting effects on labor market performance. This assumption is more difficult to evaluate; see Bound (1991a) and Parsons (1991b) for differing opinions on its validity.
} 
probability, and the potential DI benefit, as a function of individual characteristics. Marvel (1982) and Parsons (1991a) follow a reduced form approach, modelling the number of DI applications in a state/year as a function of state-level denial rates. While Marvel's results are mixed, both Halpern and Hausman and Parsons find strong effects of denial rates on applications probabilities; both estimate that the elasticity of applications with respect to changes in the denial rate is approximately $0.45 .^{5}$

\section{Unexamined Issues: Takeup and Targeting Efficiency}

One potential limitation of Parsons' (1991a) theoretical formulation, however, is that the decision to apply for DI and the decision to leave the labor force are modelled as identical. In fact, these are two distinct decisions, since there is not necessarily full takeup of DI benefits by potential applicants. That is, there may be a number of potentially eligible individuals who do not apply for the program. Low takeup for various social insurance programs has been documented in numerous other studies; Blank and Card (1991) find a takeup rate among eligible unemployment insurance claimants of only two-thirds, and Blank and Ruggles (1993) estimate a similar takeup rate for those eligible for cash payments under Aid to Families with Dependent Children (AFDC). The reasons for low takeup are not well understood, but it is generally assumed that stigma over the receipt of government assistance plays a key role (Moffitt, 1983).

It is difficult to estimate the takeup rate for DI application, since eligibility is a function of

'Parsons (1991a) notes that Marvel's (1982) results were rendered inconclusive because of a data error. Hausman and Halpern (1986) conclude that the elasticity of applications with respect to the acceptance probability is quite small, but the implied elasticity with respect to the denial rate (at the mean of the denial rate in this era) is the same as that of Parsons. Bound and Waidmann (1992) look more broadly at the general expansion of the DI program over time, rather than focusing on specific program parameters. 
both work history and underlying disability. But a rough calculation is possible, using data on the labor force attachment of older workers from the March 1978 Current Population Survey (CPS), which reports labor force information for 1977, data on DI applications and recipients in that year in Lando et al. (1982), and information on the health status of non-workers from the NHIS. We estimate that approximately $62 \%$ of eligible $45-64$ year old men were either on DI or applied for the program in that year. ${ }^{6}$ This takeup rate is approximately equal to those estimated by Blank and Card (1991) and Blank and Ruggles (1993), and suggests that there are a large number of potentially eligible applicants to the DI program who do not avail themselves of this option. This may not be surprising for a program with such an exhaustive application process, including long waiting periods, medical exams, and the possibility of multiple applications before benefits are received.

If the Parsons (1991a) theoretical formulation is augmented to allow for response along both the application and labor force participation margins, then the finding that applications fall when denial rates rise does not prove that there is a response in labor supply. This is because high denial rates may make individuals who are already not participating in the labor force reluctant to apply for the program. For the individual who is on the margin between applying and not, a smaller likelihood

\footnotetext{
${ }^{6} \mathrm{We}$ define eligibility as being in poor, fair, or good health, and being out of the labor force for at least 20 weeks in 1977. The Government Accounting Office (1989) reports that $96 \%$ of allowed DI applicants and $94 \%$ of denied applicants reported their health status as poor, fair, or good (with roughly equal divisions across the categories), so that our measure of eligibility along the health dimension uses these three categories. We use as a cutoff here working less than 32 weeks in the previous year, since individuals could have worked up to 32 weeks and still have applied for DI (due to the waiting period). For 1977 , we only have data on the total number of recipients and applicants. In 1975 , roughly $53 \%$ of the recipients were $45-64$ year old men; we assume that this same ratio applies in 1977 to both recipients and applicants. This calculation may somewhat understate the takeup rate, since a number of individuals who are out of the labor force may have already applied for DI and been rejected; these individuals should be included in the numerator of the takeup rate. Also, some individuals who are out of the labor force may not have had the earnings and work experience required to qualify for DI, although this problem is presumably fairly small for the sample of older males in this era. On the other hand, approximately five percent of applicants report themselves in excellent health, and we do not count these individuals in our takeup rate denominator.
} 
of acceptance could lower the expected benefits of application below the tangible and psychic costs of application. Evidence that such a relationship exists for the unemployment insurance program is provided by Blank and Card (1991), who find a strong negative relationship between state disqualification rates and takeup of unemployment insurance among the eligible unemployed. If takeup is similarly a function of DI denial rates, then Parsons' and Halpern and Hausman's estimated applications elasticity cannot be directly translated to a labor supply response to changes in denial rates.

Similarly, previous research on the effects of DI on individual behavior has assumed that there is no takeup response in converting effects on DI participation to effects on labor force nonparticipation, and vice-versa. ${ }^{7}$ If there is a takeup response, there will be a wedge between these two margins which must be accounted for in comparing research results.

A second issue which has been unexamined in previous empirical work is the extent to which increased denial rates efficiently target their incentives: if labor supply increases and applications fall, will the response come mostly from the truly able or the truly disabled? This question goes to the feasibility of denial rate increases as a self-screening device, to use Parsons' (1991a) terminology. He notes that it is possible that denial rate increases could have a perverse effect, reducing applications more among the disabled than among the able. Such a perverse effect could arise due to higher discount rates or capital market constraints for that group, so that they are less able to bear

\footnotetext{
'Although Bound (1989) does note that his conversion of Leonard's (1979) DI participation elasticity to a labor force non-participation elasticity requires the assumption that all applicants attracted to DI by higher benefits would otherwise be working, ie. that there is no takeup margin of response.
} 
the increased uncertainty that arises from uniform increases in screening stringency.' Parsons does provide some evidence that the quality of screening under DI, as measured by the ultimate mortality of accepted vs. rejected applications), is highest at the initial determination stage. ${ }^{9}$ But this evidence cannot resolve the important question of the differential effect of denial rate increases on more and less able applicants.

Lacking state-by-state information on the health of DI applicants in this era, we are unable to directly investigate targeting efficiency in the application decision. But it is possible to use information on the health of workers and non-workers to assess the targeting efficiency of the labor supply incentives of denial rate changes. That is, to the extent that denial rate rises cause less labor force non-participation, we can assess whether this response is occurring mostly within the able population (which would indicate efficient targeting) or the disabled population (which would indicate perverse self-screening). And, if the results indicate no takeup response to the policy change, the targeting efficiency of the labor force response can be directly translated to targeting efficiency in the applications decision.

\section{Part II: Changes in State Denial Rates}

The cross-sectional variation necessary to evaluate the effect of changes in DI allowance policy arises from increased denial rates across the U.S. states in the late 1970s, as employed by

\footnotetext{
${ }^{8}$ A full welfare analysis of this policy change, of course, also requires information on the effect of denial rate increases on the probability that truly disabled individuals are admitted to the DI rolls; we discuss this point further in the conclusions. For detailed theoretical analyses of optimal DI policy, see Diamond and Mirlees (1978) or Diamond and Sheshinski (forthcoming).

'This evidence is difficult to interpret, as Parsons notes, due to sample selection at the different stages of the application process. If the "easy cases" are dealt with at lower stages in the applications process, then it is natural for the targeting efficiency to appear to be worse at higher levels.
} 
Marvel (1982) and Parsons (1991a). As noted in Part I, the initial determination for DI is through medical examinations by state disability boards. In the mid-1970s, DI denial rates averaged approximately $54 \%$. By 1977 , however, DI tax collections had not kept pace with the rapidly expanding recipient base, and the DI trust fund faced a deficit of $20 \%$ of expenditures. The response to this funding crisis was twofold: the payroll tax rate was increased, and the denial rate at the initial stage of application was increased. As a result, denial rates rose from 53.8 percent in 1977 to 69.3 percent in $1980 . .^{10}$

This initial stage of applications, however, is not fully under the control of the federal government. Rather, the federal government can only increase denial rates by putting pressure on state DI boards to change their behavior. This pressure worked on average, as witnessed by the rise in initial denial rates nationwide; furthermore, denial rates became more uniform across the states, as the coefficient of variation fell from 0.101 to 0.090 . But the success of the federal pressure was differential across the states, as is illustrated in Table 1, which reports denial rates by state in 1977 and 1980, and the change from 1977 to 1980 . Some states, such as Connecticut and New York, saw very large increases in their denial rates, while in others the denial rates rose only slightly. It is this differential response which identifies the effect of $\mathrm{DI}$ in the empirical work below. That is, we will assess whether states which increased their denial rate the most in this era saw the largest rise in the labor force participation of older workers. The plausible exogeneity of these state level policy changes raises another advantage of studying this alternative DI policy tool, relative to focusing on potential DI benefit differences (given the inherent identification problems arising from benefits

\footnotetext{
${ }^{10}$ This is a weighted average, where the weights are the population of $45-64$ year olds in the state, as measured in the March 1978 Current Population Survey. This weighted average is taken over the 47 states (and the District of Columbia) for which we have denial rate data; we do not have data on denial rates for Arkansas, Alaska, and Hawaii. We are grateful to Donald Parsons for providing the denial rate data.
} 
which are a function of lifetime earnings).

There are three important questions to be asked about these denial rate changes. First, why is the variation from this policy change any more useful than the point in time variation in denial rates across the states? The key difference is that the point in time variation represents both administrative parameters and the nature of the application pool. In states with a higher propensity to apply for DI at a given health level (perhaps due to poor alternative labor market opportunities), the average applicant will be of better health. As a result, there will be higher denial rates for a given level of screening difficulty. Since individuals have to drop out of the labor force to apply, this will lead to a natural positive correlation between labor force non-participation and denial rates; denial rates will be highest where the most older persons are out of work. Using the change over this era provides a sharp source of variation which can separate administrative influences on the denial rate from the effect of the composition of the pool. Indeed, if our models below are identified using cross-sectional variation at a point in time (ie. if the models don't include state effects), our estimates are wrong-signed, as this explanation suggests that they might be.

Second, given the availability of an appeals option, how influential are initial denial rates for labor force participation decisions? There are two reasons why initial denials are key. First, unless the appeals process becomes more lenient at the same time that the initial screening is becoming more stringent, then increases in initial denials will lead to increases in ultimate denials. In fact, total awards fell lockstep with initial denials in the period from 1977 onwards (Lando et al., 1982). ${ }^{11}$ Second, even if the appeal is ultimately successful, the appeals process is time consuming and potentially costly in terms of foregone earnings. As Parsons (1991a) notes, an application which

"Initial denial rates actually rose slightly from 1975 to 1977 , after being flat for the early 1970 s. But ultimate awards remained flat, suggesting that state actions at the initial level were countered by the appeals process during this earlier period. 
was successful at the final level would take at least 14 months to get resolved, a figure which does not include the applicant's delay in processing each portion of the application.

Finally, can state denial rate changes be taken as independent of other state correlates of labor force behavior? For example, it may be that even in changes, the denial rate is a function of the structure of the applicant pool, so that the bias noted above remains. However, it seems unlikely that such a dramatic change in denial rates over a relatively short period could be a function of the composition of the applicant pool. Furthermore, the scenario described above would tend to bias against a finding of a negative correlation between the denial rate and labor force non-participation.

Alternatively, it could be that state decisions on how to respond to federal pressure were a function of the state of the local labor market. This type of endogenous administrative response could bias the estimates towards finding a negative correlatation between denial rates and nonparticipation, if states in which there were good labor market opportunities were the ones that increased denial rates the most (because there was less cause for generous DI as a social safety net). While we are unable to rule out this possibility, we assess the robustness of our results to the experience of outlying states below.

\section{Part III: Empirical Strategy}

The data source for the analysis is the National Health Interview Survey. This is a nationally representative survey of households which collects information on the labor force participation of each household member, a number of subjective health measures, and two objective anthropometric measures: height and weight. We use data from the NHIS for 1976 through 1978 (before the policy change) and 1980 through 1982 (afterwards). We include 1978 in our before period in order to increase the sample size and to follow Parsons (1991a); the results are similar, although somewhat 
less precisely estimated, if 1978 is excluded.

Our estimation strategy proceeds in two steps. First, we examine the effect of changes in denial rates from 1977 to 1980 on the labor force non-participation decision of 45-64 year old male workers. ${ }^{12}$ We use two NHIS questions about labor force participation: participation in the week of the interview, and participation in the previous year. We will primarily rely on the question about activity at the time of the survey in the empirical work for two reasons. First, the question about labor force participation last year changed substantially after 1981, so this limits our sample size. Second, since the waiting period for DI application is less than one year, lower non-participation due to higher denial rates may be overlooked by a measure with a one year window. ${ }^{13}$

We use these data to run regressions of the form:

(1) $\quad \mathrm{NP}_{\mathrm{ijt}}=\mathrm{f}\left(\alpha+\beta_{1} \mathrm{X}_{\mathrm{ijt}}+\beta_{2} \mathrm{DEN}_{\mathrm{jt}}+\beta_{3} \delta_{\mathrm{j}}+\beta_{4} \tau_{\mathrm{t}}+\epsilon_{\mathrm{ij}}\right)$

NP is our measure of non-participation for individual $i$ in state $j$ in year $t$. $X$ is a set of controls for other individual attributes that may affect the participation decision: age, marital status, race, and education. ${ }^{14}$ DEN is the log of the denial rate in 1977 (for the before years) or 1980 (for the after years). ${ }^{15}$ That is, we don't use the actual denial rate in each year, but rather use a "before" and "after" denial rate. In this way, we avoid short run changes in the denial rate which may reflect

${ }^{12}$ We focus on males and this age group for comparability to the previous literature.

${ }^{13}$ That is, when denial rates were low, an able individual may have taken 5 months off to apply, gotten rejected, and returned to work within the year. In that case, a rise in denial rates which caused that individual to not leave their job in the first place will not have any effect on whether there was measured labor force non-participation during the year.

${ }^{14}$ We control for age using indicator variables for being age 45-50, 51-55, and 56-60 (60-64 being the omitted group). We do not control for family income due to potential endogeneity to the labor force decision; there is no person-specific data on income, or breakdown of income by source.

${ }^{15}$ The results are insensitive to the use of the level of the denial rate; we use the log for comparability to Parson's findings. 
changes in the composition of the applicant pool, and focus on the discrete administrative change between 1977 and 1980 . In that same vein, we include state dummies $\left(\delta_{j}\right)$ to capture systematic fixed differences across states in the nature of the applicant pool and year dummies $(\tau)$ to measure other time series trends in labor force participation decisions. All regressions are run as probits. ${ }^{16}$

In this regression, we are interpreting $\beta_{2}$ as the long run response of non-participation levels to changes in the denial rate. This may not be true if individuals have not adjusted their behavior to reflect the policy change by our "after" period (1989-82). In this case, we may understate the long run change in the stock of workers from denial rate increases.

Second, we use these data to examine the targeting efficiency of changes in state denial rates. As noted above, we focus on one aspect of targeting efficiency: the differential effects of denial rate changes on the labor supply of more and less able workers. We do so using an augmented version of equation (1), which incorporates information on the health status of the applicant. That is, we run regressions of the form:

$$
\mathrm{NP}_{\mathrm{ijt}}=\mathrm{f}\left(\alpha+\beta_{1} \mathrm{X}_{\mathrm{ijt}}+\beta_{2} \mathrm{DEN}_{\mathrm{jt}}+\beta_{3} \mathrm{DIS}_{\mathrm{ijk}}+\beta_{4} \mathrm{DIS}_{\mathrm{ijt}} * \mathrm{DEN}_{\mathrm{k}}+\beta_{3} \delta_{\mathrm{j}}+\beta_{4} \tau_{\mathrm{t}}+\epsilon_{\mathrm{ij}}\right)
$$

where DIS is an indicator variable for being disabled (as defined below). In this specification, we can separately identify the effect of changes in denial rates on the able and the disabled. If changes in denial rates perfectly target their labor force incentives to those who are not truly disabled, then the coefficient $\beta_{3}$ will be negative, and the coefficient $\beta_{4}$ will be of the opposite sign and same magnitude (so that there is no net effect on the disabled). On the other hand, if the incentive effect

\footnotetext{
${ }^{16}$ The results for both the basic labor force non-participation model (1) and the targeting efficiency model (2) are quite similar if linear probability models or logits are estimated instead. Note that the fact that the variable of interest only varies at the state/year level might lead us to understate our standard errors, if there is significant within state/year cell correlation in labor force non-participation. Adjusting the standard errors to allow for general intra-state/year correlation has no effect on the inferences that we draw below.
} 
is equal across all categories of health, then the interaction term will be zero.

There is no precise objective measure of disability in the NHIS data. Previous research using the NHIS has measured health status using self-assessed health, but a number of articles have noted that such self-assessed indicators are problematic in the context of labor supply equations. ${ }^{17}$ Thus, we use instead an objective anthropometric measure of disability: the Body Mass Index, or BMI, which is (body mass in kilograms)/(height in meters) ${ }^{2}$. A number of studies have documented a strong U-shaped correlation between the BMI and both objective and subjective health indicators. Waaler (1984) studied the relationship between BMI and mortality in a sample of 1.8 million Norwegian residents over the 1963 to 1979 period. He found a marked U-shaped relationship between BMI and subsequent mortality, with mortality for older men being much higher outside the BMI range of 21-30. There was a strong U-shaped relationship between BMI and obstructive lung disease, stomach cancer, and cerebrovascular disease and a shallow $\mathrm{U}$ shaped relationship for cardiovascular disease and diabetes. These findings are echoed in the large body of work surveyed by Kushner (1993), who notes that the National Academy of Sciences recommends a BMI of approximately 22-28 for 45-64 year old men. And Costa (1993) finds a similar relationship between BMI and self-reported health, medical utilization, and labor force non-participation.

The fact that obese men are of poorer health status is uncontroversial, and there are a number of underlying biological explanations for this relationship, such as the effect of fat intake on cardiovascular disease (Kushner, 1993). But there is some debate over the causality in the underweight/poor health nexus, since morbidity will generally lead to weight loss, so that those who

\footnotetext{
${ }^{17}$ In particular, many of the self-assessed measures are defined in terms of ability to work, rendering them clearly endogenous in a labor supply model. The strengths and weaknesses of selfassessed health status are discussed in Parsons (1982) Anderson and Burkhauser (1985), Bazzoli (1985), Butler et al. (1987), and Bound (1989b).
} 
are sick will be both of lower weight and face a higher mortality risk. A number of studies, however, have excluded individuals who died within several years after measurement in order to control for this reverse causality, and have still found a U-shaped relationship to BMI. ${ }^{18}$ Thus, we will take the BMI as an objective indicator of disability for the purposes of estimating (2).

The relationship between BMI, self-reported (poor or fair) health status, and labor force nonparticipation is documented for our sample of older men in Figure 1. There is a strong U-shaped relationship with being in poor or fair health, and a somewhat shallower but still pronounced relationship with labor force participation. This parallels the findings of Costa (1993) for the 19851991 period. Based on the correlation of BMI and self-reported health status, and on the previous literature, we use three categories of BMI to measure disability, in order of severity: BMI less than 22 or greater than 28; BMI less than 21 or greater than 32; and BMI less than 20 or greater than 34. ${ }^{19}$

The means of the NHIS data are reported in Table 2, for our full sample of 45-64 year old males, and separately for those in and out of the labor force last week. Being more highly educated, married, and younger is correlated with being in the labor force last week. For our disability measures, we divide the proportion reporting disability into those who are underweight (for their height) and those who are overweight. Being either under and overweight is associated with higher labor force non-participation, although the correlation seems stronger in the former case. $44 \%$ of older males are "disabled" according to our most broad definition of disability; only $19 \%$ are in our

\footnotetext{
${ }^{18}$ For example, Waaler excluded individuals who died within five years of BMI measurement; see Kushner (1993) for a discussion of several other studies that also used this approach and obtained similar results.

${ }^{19}$ We use larger increments on the overweight end of the scale because, as Figure 1 and previous research documents, the gradient of the health relationship is less steep than on the underweight end of the scale.
} 
most narrow BMI group.

\section{Part IV: Denial Rates and Labor Force Non-Participation}

\section{Basic Results}

Our estimates for equation (1) are reported in Table 3. The first column reports the effect on non-participation in the last week, and in the second column non-participation in the last year is the dependent variable. Since the probit coefficients are not directly interpretable, the figures in square brackets show the effect of a $10 \%$ increase in the denial rate on non-participation rates. In both cases, the results indicate that higher denial rates are associated with a lower rate of nonparticipation. For non-participation in the last week, the estimate is significant, and implies that a $10 \%$ increase in the denial rate leads to a 0.46 percentage point decrease in non-participation. At the mean level of non-participation in our sample (17.3\%), this represents a response elasticity of -0.27 .

A $10 \%$ increase in the denial rate lowers non-participation in the last year by 0.3 percentage points, but the estimate is only significant at the $14 \%$ level. However, non-participation is lower by this measure, so that the estimated elasticity of non-participation, -0.23 , is similar to that using nonparticipation last week. For the reasons noted above, participation in the previous week is the preferred measure of labor force attachment for this exercise, and we will rely on that measure for the remainder of the empirical work; the results are all similar if participation last year is used.

The covariates in the model are all highly significant. Being married or more highly educated lowers the probability of being out of the labor force both in the previous week and the previous year. Being non-white raises the probability of non-participation in the last week, but lowers it in the last year, perhaps reflecting more transitory labor force attachment for this group. The 
probability of non-participation rises uniformly with age. The results are unchanged if the three age group dummies are replaced with 19 single year age dummies.

One potential problem with our approach, noted above, is that there may be an endogenous legislative response to local labor market conditions in setting DI denial rates. Indeed, examining Table 1, a clear regional pattern in denial rate changes is apparent, with the largest increases in Connecticut, New Jersey, New York, and Pennsylvania. Given their magnitude, these sharp increases are unlikely to reflect changes in the composition of the applicant pool alone, and are almost certainly dominated by policy variation. ${ }^{20}$ These increases may, however, reflect a regionspecific shock which was correlated with the decision to raise denial rates sharply. If this shock also caused decreased non-participation among older workers, it could bias our findings.

In order to control for this, in the next column of Table 3 we include a set of 4 region dummies (Northeast, Midwest, South, West), interacted with a dummy for being after the denial rate policy change. In this model, the effect of the policy is identified by within-region changes in denial rates and in labor force non-participation. Including these region interactions substantially increases the estimated standard error on the denial rate, but the coefficient estimate is quite similar. Thus, our finding is not just driven by a trend in participation in the Northeast vs. the rest of the country.

\section{Interpreting the Basic Finding}

The basic regression results are supportive of the contention that DI denial rates matter for labor force decisions. Even in the absence of a behavioral response among workers, however, an increase in the denial rate would lead to an decrease in the number of labor force non-participants,

\footnotetext{
${ }^{20}$ Starting from a denial rate of $55 \%$, even if the number of individuals applying for DI rose by $30 \%$, and all these new individuals were totally unqualified and were rejected by state administrators, the average denial rate would only rise by $20 \%$.
} 
so long as some of those denied workers return to work. Thus, our estimate combines two effects: the effect on those denied applicants returning to work, and the effect of those persons who never leave work to apply for DI. We will label the former the "return to work" effect, and the latter the participation response.

Separating these two effects is difficult, since we do not have precise information on the fraction of denied applicants returning to work. But a rough calculation is possible. In 1977, there were 1.24 million applications to DI. A $10 \%$ increase in the denial rate corresponds to 66,500 more denials. Given the size of the 45-64 year old male population in this era (20.7 million persons), our estimates imply that a $10 \%$ denial rate rise led to an increase in the number of workers of 95,360 . Thus, even if all of the denied applicants had returned to work, our estimates would still imply some participation response.

Estimates of the likelihood of returning to work in this era are presented in Bound (1989) and Parsons (1991b). Bound's estimates that, 18 months or more after denial, $45 \%$ of denied applicants had returned to work (at least part-time). Parsons finds that $75 \%$ of denied applicants who are alive and not receiving government assistance are working 5 years after application. ${ }^{21}$ Using these two figures to bound the true return to work effect, our estimates imply that between 45,500 and 68,800 older male workers remained on the job rather than leave to apply for the DI program. The implied elasticities of non-participation (accounting for the participation response only) are between -0.13 and -0.20 , with the remainder of the estimated -0.27 effect arising from the return to work of denied

\footnotetext{
${ }^{21}$ Bound (1991a), in turn, criticizes Parsons' calculation by noting that the sample of living nonpublic assistance recipients is a selected one. His corrected estimate using the same sample is $60 \%$.
} 
applicants. $^{22}$

As a point of comparison, it is useful to compare our estimate to the findings of the literature on potential DI benefits and labor force non-participation. The estimated effects in that literature range from an upper bound of 0.63 to 1.80 in Parsons (1980) to a lower bound of 0.06 in Haveman and Wolfe (1984). Most of the studies subsequent to Parsons (Leonard, 1979; Halpern and Hausman, 1986) have estimated non-participation elasticities in the range of 0.1 to 0.2 . It is difficult to compare the effects of a benefit cut and an denial rate rise from the perspective of a given individual, but they can be compared from the perspective of the program budget constraint. In steady state, a $10 \%$ cut in benefits has the same revenue implications as a $10 \%$ fall in the DI acceptance rate. ${ }^{23}$ A $10 \%$ fall in the DI acceptance rate, in turn, corresponds to a $9.1 \%$ rise in the denial rate in this era. Our estimates imply that a $9.1 \%$ rise in the denial rate would lead to a 1.2 to $1.8 \%$ fall in non-participation (focusing only on the participation response). Thus, according to this metric, our findings are in the same range as the post-Parsons benefits literature.

Another important point of comparison, given the earlier discussion, is with Parsons' (1991a) and Halpern and Hausman's (1986) applications elasticity of 0.45. Given the number of applications to DI in 1977 , this implies a fall in applications of 55,600 , which is in the middle of our estimated participation response of 45,500 to 68,800 persons. Even using the lower bound estimate, there does not appear to have been a significant applications response among those already out of the labor force. Our findings therefore imply that, unlike the case of unemployment insurance studied by

\footnotetext{
${ }^{22}$ If individuals return to work slowly once denied, we may miss their return in our after (198082) period. Once again, this will bias downward our long run estimate of the total impact on the labor force, although not our estimate of the non-participation elasticity.

${ }^{23}$ In transition, the benefits cut saves more money, because it will be both prospective to future applicants and retrospective to current recipients. So this statement is only true out of steady state if the benefits cut is a prospective one.
} 
Blank and Card (1991), takeup of DI benefits among the ex-ante eligible does not respond to the stringency of the screening process in a significant way. This has the implication that applications/program participation elasticities can be readily transformed into labor supply responses, as has been done in previous work.

\section{Part V: The Targeting Efficiency of Raising Denial Rates}

As noted above, it is ambiguous ex ante whether increasing denial rates can effectively target the labor force incentives of DI policy. In fact, it is theoretically plausible that denial rate rises can have a perverse effect, with a larger response among the truly disabled, if this group has (for example) higher discount rates or faces more binding capital market constraints. We investigate this question within the regression framework (3), using the anthropometric measure of disability BMI.

Table 4 reports the regression results. We report only the coefficients of interest from regressions that include all of the controls shown in Table 3. The first column replicates the basic regression from Table 3. The second column includes our first BMI category as a control variable. This variable is highly significant, and indicates that being in this BMI category raises the probability of non-participation by $15 \%$. There is little effect on the denial rate coefficient from including this control.

In the third column, we interact the denial rate with the BMI indicator variable. The denial rate coefficient rises somewhat, while the interaction is positive, although not significant. The results therefore imply that the labor supply effect of the denial rate increase was smaller on less able older males: for "able" persons, non-participation falls by 0.57 percentage points for every $10 \%$ denial rate rise, while for the "disabled", the fall is only 0.35 percentage points. This suggests that there is some targeting efficiency to this policy. 
In the remaining columns of Table 4 we tighten our definition of disability (ie. the last measure excludes more of the middle of the BMI distribution than the first measure). In each case, the coefficient on the denial rate itself is unchanged when BMI is added to the regression (the fourth and sixth columns). But the evidence of targeting efficiency increases as these more stringent definitions are used. For the second definition, the interaction term is significant, and indicates that a $10 \%$ denial rate rise had an effect on disabled workers which was less than half that of able workers.

For the most stringent definition, which labels individuals as disabled only if they have BMI below 20 or above 34 , increasing denial rates is estimated to have no effect on the participation of the disabled. For able workers, the estimated effect is now larger, with a $10 \%$ denial rise leading to a 0.61 percentage point non-participation rise. This measure also has the largest mean effect on labor force participation (column (6)); being disabled by this metric raises the probability of nonparticipation by $29 \%$.

This striking finding suggests that denial rate increases are an effective means of targeting the labor market incentive effects of DI policy towards able workers. For workers who are labeled as able by our most stringent BMI measure, the $30 \%$ denial rate rise from 1977-1980 led to a $11.1 \%$ rise in non-participation. But for those labeled disabled, there was no effect. Furthermore, our earlier finding that all of the estimated drop in applications to DI in response to this policy change can be traced to decreased labor force non-participation suggests that the reduction in applications occurred solely among the able as well.

If the denied applicants are disproportionately able, we would expect a larger effect on the labor force participation of that group due to the return to work effect. But even if all denied applicants were in the $80 \%$ of the population labelled most able by our third BMI measure, and even 
if all denied applicants return to work, it could not explain the difference between the estimated effects on that group in Table 4 and those on the total population in Table 3.24

\section{Part VI: Conclusions}

Disability insurance has grown rapidly in the U.S. over the past thirty years. While program growth slowed in the late 1970s and early 1980s, it has risen again in recent years, so that the DI program faces an imminent financing crisis. This rapid growth has been criticized on the grounds that imperfect targeting and high benefits cause able individuals to use this program to subsidize early retirement. This criticism, in turn, has given rise to a large literature on the effects of potential DI benefits on labor force participation. But there has been little emphasis on the other policy tools at the disposal of DI policy makers.

We have examined one such policy tool, the denial rate for initial DI applications. We did so by exploiting the large rise in denial rates across the states in the late 1970 s. We found that increased denial rates did lead to decreases in labor force non-participation, suggesting that there is some moral hazard involved with the imperfect targeting of DI. Our estimated incentive effects lie within the range of recent estimates of the effect of potential DI benefits on labor force nonparticipation. Furthermore, taken in conjunction with earlier evidence on the applications response to denial rate changes, our findings suggest that there is little harm in translating applications

\footnotetext{
${ }^{24}$ In the entire population, if all denied applicants returned to work, the effect of a $10 \%$ denial rate rise would be to lower the labor force non-participation rate by 0.0032 percentage points. If all these returners were in $81 \%$ of older males labelled able by our third BMI definition, this would represent a rise for this group only of 0.0037 percentage points. This 0.0005 percentage point difference is much smaller than the 0.0015 percentage point difference between the implied effects of a 10\% denial rate rise in column (1) of Table 3 and column (7) of Table 4 (for the able group).
} 
responses directly into labor force responses; there is no evidence that the takeup rate for DI benefits responds to denial rate changes.

We also found that the increase in work incentives appears to have been efficiently targeted to the more able portion of the older male population. In particular, using our most narrow definition of anthropometric disability, we estimate that there was a large $11.1 \%$ reduction in the non-participation on able workers from this $30 \%$ denial rate rise, and no effect on the participation of disabled workers. This suggests that, conditional on the same mean labor force incentive effect as other policies, denial rate increases may be an effective means of reducing the moral hazard problems induced by DI. Furthermore, since our estimates can completely account for the drop in applications by the increased participation of able workers, they imply that this policy was efficiently targeted along the applications margin as well.

Of course, our findings only solve half of the puzzle for the government policy-maker who is evaluating the optimal level of the DI denial rate. An efficient increase in screening would lower both the Type I and Type II errors of the process. But uniform increases in denials may lower Type I error while raising Type II error, even among those truly disabled persons who continued to apply for the program. That is, even if applications don't fall among the truly disabled, there may still be a fall in the rate at which they are accepted onto the DI program.

This lowered probability of acceptance for truly disabled individuals imposes a welfare cost which must be weighed against the reduced distortions to labor supply for more able workers. Data on the health of accepted and rejected DI applicants before and after the denial rate increases could be potentially used to directly measure the ratio of increased Type II to reduced Type I error, in an effort to fully assess the welfare implications of this policy change. 


\section{References}

Anderson, Kathryn and Richard Burkhauser (1985). "The Retirement-Health Nexus: A New Measure of an Old Puzzle," Journal of Human Resources, 20:315-330.

Bazzoli, Gloria (1985). "The Early Retirement Decision: New Empirical Evidence on the Influence of Health," Journal of Human Resources, 20:214-234.

Blank, Rebecca and David Card. "Recent Trends in Insured and Uninsured Unemployment: Is There an Explanation?," Quarterly Journal of Economics 106, November 1991, 1157-1190.

Blank, Rebecca and Patricia Ruggles. "When Do Women Use AFDC \& Food Stamps? The Dynamics of Eligibility vs. Participation," mimeo, July 1993.

Bound, John (1989). "The Health and Earnings of Rejected Disability Applicants," American Economic Review, 79, 482-503.

Bound, John (1991). "The Health and Earnings of Rejected Disability Applicants: Reply," American Economic Review, 81, 1427-1434.

Bound, John (1991b). "Self-Reported Objective Measures of Health in Retirement Models," Lournal of Human Resources, 26, 106-138.

Bound, John and Timothy Waidmann (1992). "Disability Transfers, Self-Reported Health, and the Labor Force Attachment of Older Men: Evidence from the Historical Record," Ouarterly Journal of Economics, 107, 1393-1420.

Butler, J., Richard Burkhauser, Jean Mitchell, and Theodore Pincus (1987). "Measurement Error in Self-Reported Health Variables," Review of Economics and Statistics, 69: 644-650.

Costa, Dora L. (1994). "Working With Pain: Disability and Labor Force Participation, 1900-1991". Mimeo, MIT.

Diamond, Peter A., and James A. Mirlees (1978). "A Model of Social Insurance with Variable Retirement," Journal of Public Economics, 10, 295-336.

Diamond, Peter A., and Eytan Sheshinski. "Economic Aspects of Optimal Disability Benefits," Journal of Public Economics, forthcoming.

Government Accounting Office (1989). Social Security Disability: Denied Applicants' Health and Financial Status Compared With Beneficiaries'. Washington, D.C.: GAO, HRD-90-2.

Halpern, Janice, and Jerry A. Hausman (1986). "Choice Under Uncertainty: A Model of Applications For the Social Security Disability Insurance Program," Journal of Public Economics, 31, 131-161. 
Hausman, Jerry A. and David A. Wise (1985). "Social Security, Health Status, and Retirement," In Pensions. Labor, and Individual Choice, Ed. Wise, D. Chicago: The University of Chicago Press.

Haveman, Robert H., and Barbara L. Wolfe (1984). "The Decline in Male Labor Force Participation: Comment, Journal of Political Economy, 92:532-541.

Kushner, Robert F. (1993). "Body Weight and Mortality," Nutrition Reviews, 51: 127-136.

Lando, Mordechai E. et al. (1982). "Recent Trends in the Social Security Disability Insurance Program," Social Security Bulletin, 45, 3-14.

Leonard, Jonathan S. (1979). "The Social Security Disability Program and Labor Force Participation," NBER Working Paper No. 392.

Leonard, Jonathan S. (1986). "Labor Supply Incentives and the Disincentives for Disabled Persons," In Disability and the Labor Market: Economic Problems. Policies, and Programs, Ed. Berkowitz, M. and M. A. Hill. Ithaca, NY: ILR Press.

Lumsdaine, Robin and David Wise (1990). "Aging and Labor Force Participation: A Review of Trends and Explanations," NBER Working Paper 3420, August.

Marvel, Howard P. (1982). "An Economic Analysis of the Operation of Social Security Disability Insurance," Journal of Human Resources, 17, 393-412.

Min-Lee, I, et al. "Body Weight and Mortality: A 27-year Follow-up of Middle-aged Men," Journal of the American Medical Association, 270: 2823-2828.

Moffitt, Robert (1983). "An Economic Model of Welfare Stigma," American Economic Review, 73:1023-1035.

Parsons, Donald (1980). "The Decline of Male Labor Force Participation," Journal of Political Economy, 88, 117-134.

Parsons, Donald (1982). "The Male Labour Force Participation Decision: Health, Reported Health, and Economic Incentives," Economica, 49:81-91.

Parsons, Donald (1991a). "Self-Screening in Targeted Public Transfer Programs," Journal of Political Economy, 99, 859-876.

Parsons, Donald (1991b). "The Health and Earnings of Rejected Disability Insurance Applicants: Comment," American Economic Review, 81, 1419-1426.

U.S. Congress, House Committee on Ways and Means (1993). Qverview of Entitlement Prosrams, U.S. Department of Health and Human Services (1990) 
Waaler, Hans T. (1984). "Height, Weight, and Mortality: The Norwegian Experience," Acta Medica Scandinavia [Suppl., 679: 1-56. 
Figure 1

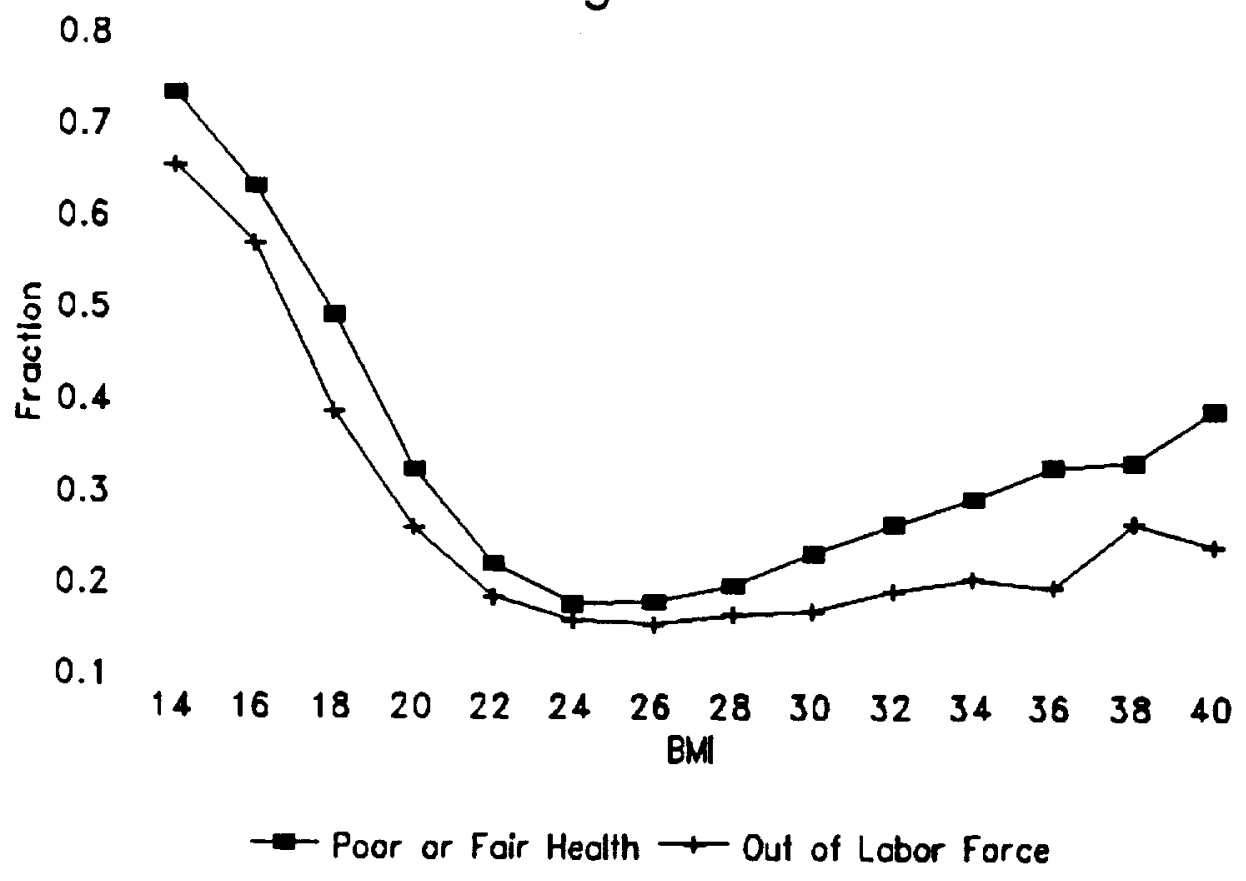


Table 1: Denial Rates Across States and Over Time

\begin{tabular}{|c|c|c|c|}
\hline State & Denial Rate 1977 & Denial Rate 1980 & Percentage Change \\
\hline $\mathrm{AL}$ & 64.5 & 69.3 & 7.4 \\
\hline$A Z$ & 51.9 & 64.8 & 24.9 \\
\hline $\mathrm{CA}$ & 55.6 & 69.3 & 24.6 \\
\hline $\mathrm{CO}$ & 55.5 & 64.9 & 16.9 \\
\hline $\mathrm{CT}$ & 47.3 & 76.2 & 61.1 \\
\hline DE & 52.1 & 54.7 & 5.0 \\
\hline FL & 58.1 & 71.4 & 22.9 \\
\hline GA & 56.8 & 76.5 & 34.7 \\
\hline ID & 56.5 & 72.5 & 28.3 \\
\hline IL & 59.1 & 67.2 & 13.7 \\
\hline IN & 50.7 & 63.5 & 25.2 \\
\hline IA & 48.8 & 65.6 & 34.4 \\
\hline KS & 50.3 & 61.6 & 22.5 \\
\hline $\mathbf{K Y}$ & 60.5 & 69.8 & 15.4 \\
\hline LA & 58.1 & 74.5 & 28.2 \\
\hline ME & 53.5 & 66.3 & 23.9 \\
\hline MD & 60.3 & 69.0 & 14.4 \\
\hline MA & 54.8 & 67.8 & 23.7 \\
\hline MI & 54.4 & 72.8 & 33.8 \\
\hline $\mathrm{MN}$ & 47.7 & 63.7 & 34.4 \\
\hline MS & 59.8 & 71.2 & 19.1 \\
\hline MO & 54.0 & 64.8 & 20.0 \\
\hline MT & 55.4 & 65.5 & 18.2 \\
\hline $\mathrm{NE}$ & 48.3 & 57.5 & 19.0 \\
\hline NV & 56.4 & 67.3 & 19.3 \\
\hline NH & 56.9 & 76.6 & 34.6 \\
\hline NJ & 40.2 & 59.3 & 47.5 \\
\hline
\end{tabular}




\begin{tabular}{|c|c|c|c|}
\hline State & Denial Rate 1977 & Denial Rate 1980 & Percentage Change \\
\hline NM & 66.7 & 73.1 & 9.6 \\
\hline NY & 47.8 & 79.7 & 66.7 \\
\hline NC & 54.1 & 65.3 & 20.7 \\
\hline ND & 55.3 & 67.9 & 22.8 \\
\hline $\mathrm{OH}$ & 49.5 & 65.0 & 31.3 \\
\hline OK & 59.6 & 72.9 & 22.3 \\
\hline OR & 60.9 & 66.5 & 9.2 \\
\hline PA & 47.4 & 73.4 & 54.9 \\
\hline RI & 46.9 & 53.9 & 14.9 \\
\hline SC & 57.2 & 70.2 & 22.7 \\
\hline SD & 52.3 & 59.3 & 13.4 \\
\hline TN & 62.4 & 72.3 & 15.9 \\
\hline TX & 60.6 & 69.8 & 15.2 \\
\hline UT & 50.7 & 62.5 & 23.3 \\
\hline VT & 49.6 & 65.9 & 32.9 \\
\hline VA & 61.3 & 68.0 & 10.9 \\
\hline WA & 53.0 & 70.1 & 32.3 \\
\hline$w V$ & 60.4 & 76.2 & 26.2 \\
\hline WI & 47.5 & 57.4 & 20.8 \\
\hline WY & 59.3 & 71.2 & 20.1 \\
\hline Weighted Average & 53.8 & 69.3 & 30.1 \\
\hline
\end{tabular}

Notes: Figures are average denial rates for the state/year cell. 


\begin{tabular}{|c|c|c|c|}
\hline & Full Sample & $\begin{array}{l}\text { In Labor Force } \\
\text { Last Week }\end{array}$ & $\begin{array}{c}\text { Out of Labor } \\
\text { Force } \\
\text { Last Week }\end{array}$ \\
\hline Out of Labor Force last week & $\begin{array}{c}.1726 \\
{[.3779]}\end{array}$ & & \\
\hline Out of Labor Force last year & $\begin{array}{l}.1313 \\
{[.3377]}\end{array}$ & $\begin{array}{l}.0136 \\
{[.1157]}\end{array}$ & $\begin{array}{c}.7065 \\
{[.4554]}\end{array}$ \\
\hline Years of Education & $\begin{array}{c}11.51 \\
{[3.569]}\end{array}$ & $\begin{array}{c}11.83 \\
{[3.435]}\end{array}$ & $\begin{array}{c}9.976 \\
{[3.790]}\end{array}$ \\
\hline Married (\%) & 85.25 & 87.36 & 75.15 \\
\hline Nonwhite (\%) & 9.021 & 8.20 & 12.96 \\
\hline Age 45-49 (\%) & 26.20 & 29.43 & 11.21 \\
\hline Age 50-54 (\%) & 26.54 & 28.90 & 15.27 \\
\hline Age $55-59(\%)$ & 25.21 & 25.22 & 25.20 \\
\hline Age $60-64(\%)$ & 21.95 & 16.45 & 48.32 \\
\hline BMII $(\mathrm{BMI}<22$, BMI $>28)$ & 43.87 & 42.65 & 49.61 \\
\hline $\mathrm{BMI}<22(\%)$ & 10.15 & 9.321 & 14.03 \\
\hline $\mathrm{BMI}>28(\%)$ & 33.72 & 33.33 & 35.58 \\
\hline BMI2 $(\mathrm{BMI}<21, \mathrm{BMI}>32)$ & 24.25 & 22.93 & 30.43 \\
\hline $\mathrm{BMI}<21(\%)$ & 5.539 & 4.735 & 9.291 \\
\hline BMI > $32(\%)$ & 18.71 & 18.19 & 21.14 \\
\hline BMI3 $(\mathrm{BMI}<20, \mathrm{BMI}>34)$ & 18.86 & 17.81 & 23.72 \\
\hline $\mathrm{BMI}<20(\%)$ & 2.680 & 2.089 & 5.441 \\
\hline $\mathrm{BMI}>34(\%)$ & 16.18 & 15.72 & 18.28 \\
\hline Number of Obs & 60825 & 50324 & 10501 \\
\hline
\end{tabular}

Notes: Figures from authors' tabulations of the 1976-1978 and 1980-1982 NHIS data (except for out of labor force last year, which is only consistently reported through 1981). 


\begin{tabular}{||cccc||}
\hline \multicolumn{4}{|c|}{$\begin{array}{c}\text { Table 3: The Effect of Denial Rate Increases on Labor Force Participation } \\
\text { Dependent Variable is a Dummy for Labor Force Non-Participation }\end{array}$} \\
& NP Last Week & NP Last Year & Region*Time \\
\hline & -.2160 & -.1678 & -.2060 \\
& $(.0924)$ & $(.1125)$ & $(.1526)$ \\
& {$[-.0046]$} & {$[-.0030]$} & {$[-.0044]$} \\
Denial Rate & -.4664 & -.2102 & -.4664 \\
& $(.0167)$ & $(.0206)$ & $(.0167)$ \\
Married & .1136 & -.0733 & .1143 \\
& $(.0218)$ & $(.0279)$ & $(.0218)$ \\
Nonwhite & -.0671 & -.0506 & -.0671 \\
& $(.0018)$ & $(.0022)$ & $(.0018)$ \\
Education & -1.130 & -1.418 & -1.131 \\
& $(.0192)$ & $(.0249)$ & $(.0192)$ \\
Age 45-49 & -.9730 & -1.150 & -.9732 \\
& $(.0180)$ & $(.0216)$ & $(.0180)$ \\
Age 50-54 & -.6370 & -.7250 & -.6377 \\
& $(.0167)$ & $(.0190)$ & $(.0167)$ \\
Age 55-59 & 60825 & 51101 & 60825 \\
& & & \\
\hline
\end{tabular}

Notes: Standard errors in parentheses; probability increase from $10 \%$ denial rate rise in square brackets. All regressions run as probits. All regressions include a full set of state and year dummies. Column (3) includes interaction of 4 region dummies with a dummy for being after the policy change. 
34

\begin{tabular}{|c|c|c|c|c|c|c|c|}
\hline \multicolumn{8}{|c|}{$\begin{array}{l}\text { Table 4: Targeting Efficiency } \\
\text { Dependent Variable is a Dummy for Labor Force Non-Participation }\end{array}$} \\
\hline & (1) & (2) & (3) & (4) & (5) & (6) & (7) \\
\hline Denial Rate & $\begin{array}{c}-.2160 \\
(.0924) \\
{[-.0046]}\end{array}$ & $\begin{array}{c}-.2228 \\
(.0924) \\
{[-.0048]}\end{array}$ & $\begin{array}{c}-.2684 \\
(.0975) \\
{[-.0057]}\end{array}$ & $\begin{array}{c}-.2209 \\
(.0925) \\
{[-.0047]}\end{array}$ & $\begin{array}{c}-.2598 \\
(.0954) \\
{[-.0055]}\end{array}$ & $\begin{array}{c}-.2193 \\
(.0925) \\
{[-.0047]}\end{array}$ & $\begin{array}{c}-.2852 \\
(.0949) \\
{[-.0061]}\end{array}$ \\
\hline $\begin{array}{c}\mathrm{BMI}<22, \mathrm{BMI}>28 \\
\text { (BMII) }\end{array}$ & & $\begin{array}{l}.1215 \\
(.0139) \\
{[.0264]}\end{array}$ & $\begin{array}{l}.1735 \\
(.0378) \\
{[.0378]}\end{array}$ & & & & \\
\hline $\begin{array}{l}\text { Denial Rate * } \\
\text { BMII }\end{array}$ & & & $\begin{array}{l}.1017 \\
(.0689) \\
{[.0022]}\end{array}$ & & & & \\
\hline $\begin{array}{c}\mathrm{BMI}<21, \mathrm{BMI}>32 \\
\text { (BMI2) }\end{array}$ & & & & $\begin{array}{l}.2154 \\
(.0176) \\
{[.0487]}\end{array}$ & $\begin{array}{c}.2901 \\
(.0482) \\
{[.0666]}\end{array}$ & & \\
\hline $\begin{array}{l}\text { Denial Rate * } \\
\text { BM12 }\end{array}$ & & & & & $\begin{array}{l}.1401 \\
(.0842) \\
{[.0030]}\end{array}$ & & \\
\hline $\begin{array}{c}\mathrm{BMI}<20, \mathrm{BMI}>34 \\
\text { (BMI3) }\end{array}$ & & & & & & $\begin{array}{c}.2232 \\
(.0213) \\
{[.0510]}\end{array}$ & $\begin{array}{c}.3947 \\
(.0592) \\
{[.0939]}\end{array}$ \\
\hline $\begin{array}{l}\text { Denial Rate * } \\
\text { BMI3 }\end{array}$ & & & & & & & $\begin{array}{c}.3078 \\
(.0994) \\
{[.0067]}\end{array}$ \\
\hline Number of obs & 60825 & 60825 & 60825 & 60825 & 60825 & 60825 & 60825 \\
\hline
\end{tabular}

Notes: Standard errors in parentheses; probability increase from $10 \%$ denial rate rise in square brackets. All regressions run as probits. All regressions include the covariates shown in Table 3, as well as a full set of state and year dummies. 